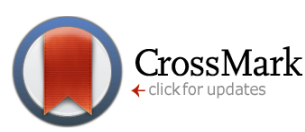

terickior upudetes

\title{
Rationale for stem cell therapy for type 2 diabetes mellitus
}

\author{
Kumar Sushaniba \\ Private Medical Center, La Habana, Cuba
}

\section{*For correspondence:}

sushanibakumar@gmail.com

Competing interests: The authors declare that no competing interests exist.

Received: 20 January 2017 Accepted: 20 February 2017 Published: 28 February 2017

Copyright The Author(s) 2017. This article is published with open access by BioMedPress (BMP).

This article is distributed under the terms of the Creative Commons Attribution License (CC-BY 4.0) which permits any use, distribution, and reproduction in any medium, provided the original author(s) and the source are credited.

\section{Abstract}

Stem cells can be differentiated into many types of mature cells. Among degenerative diseases, type 1 diabetes mellitus (T1DM) is considered to be a good target disease for stem cell therapeutic application. Indeed, several studies have suggested that stem cells can be differentiated, both in vitro and in vivo, into beta cells which regenerate the pancreas. However, recent studies have shown that stem cell therapy can also provide benefits for type 2 diabetes mellitus (T2DM), which is not related to beta cell degeneration in the pancreas. This commentary will discuss the opportunity to use mesenchymal stem cells (MSCs) to treat T2DM, citing various stem cell therapies from recent published studies. Indeed, a current report "Expanded autologous adipose derived stem cell transplantation for type 2 diabetes mellitus, Biomedical Research and Therapy, 3(12): 1034-1044" evaluated and confirmed the positive effects of stem cell transplantation for blood glucose regulation in T2DM.

\section{Keywords}

Stem cells; Mesenchymal stem cells; Type 2 diabetes mellitus, T2DM

\section{T1DM versus T2DM}

Diabetes mellitus (DM) is a metabolic disease that causes the accumulation of high glucose levels in the blood. Patients with DM usually exhibit particular symptoms, including frequent urination, increased thirst and increased hunger (in the early phase of the disease), and complications such as diabetic ketoacidosis, non-ketotic hyperosmolar coma, heart disease, stroke, chronic 
kidney failure, foot ulcers and damage to the eyes (in the late phase). The high blood glucose level in DM patients relates to reduction of insulin; beta cells in the pancreas cannot produce enough insulin for usage or cells in the body cannot properly respond to insulin.

Based on differences in mechanisms, DM can be classified into 2 main types: Type 1 DM (T1DM) and Type 2 DM (T2DM). T1DM results when beta cells cannot produce enough insulin for cells of the body. This condition is considered akin to an autoimmune disease since beta cells are destroyed by the immune system. T1DM is common in children and, therefore, is also known as juvenile diabetes. T2DM is different from T1DM in that the beta cells of T2DM patients are able to produce enough insulin; however, the cells of the body cannot use this form of insulin and are said to be "insulin resistant". Since T2DM is not related to insulin; it is regarded as a non-insulin dependent diabetes mellitus.

T1DM, as a degenerative disease, has rapidly attracted stem cell scientists to develop new stem cell based approaches in attempts to treat it. Indeed, T1DM has been viewed by two different perspectives, including as a degenerative disease which lacks beta cells and as an autoimmune disease in which the immune system attacks the beta cells. For this first strategy, both stem cells and insulin-producing cells differentiated from stem cells were used to treat T1DM in both preclinical trials and clinical trials (Xv et al., 2016).

\section{T2DM treatment by stem cell transplantation}

Recently, the Pham group reported some cases of T2DM treatment using autologous adipose derived stem cells (ADSCs) (Le et al., 2016). In their study, adipose tissue was collected from patients. ADSCs were extracted and expanded from adipose tissue. The cells were confirmed to be normal stem cells with normal karyotype, and negative for endotoxin and mycoplasma. The T2DM patients received a transplant of ADSCs at a dose of $1-2.10^{6} \mathrm{cell} / \mathrm{s} / \mathrm{kg}$. The results showed that after 3 months, blood glucose levels of patients were significantly reduced and there were no adverse effects. From literature searches, only 3 other clinical studies were found which used stem cells to treat T2DM.

There have been two clinical trials using autologous bone marrow mononuclear stem cells (BM-MNSCs). The first clinical trial was performed in 6 patients who were infused with BM-MNSCs in the celiac and superior mesenteric arteries, without any myeloablative or immunosuppressive pretreatment (Wehbe et al., 2016). The results showed that $5 / 6$ patients (83\%) showed an increase of fasting glucose levels and a decrease of glycosylated hemoglobin ( $\mathrm{HbA} 1 \mathrm{C})$, significantly reducing their medication requirements. Of note, 3/6 patients (50\%) showed improvement in diabetic complications and did not show any significant adverse effects (Wehbe et al., 2016). 
The second clinical study also used BM-MNSCs to treat T2DM patients. Here, patients were confirmed as T2DM, for greater than 5 years, with oral antidiabetic drugs along with insulin levels ( $\geq 0.4 \mathrm{lU} / \mathrm{Kg} /$ day) and $\mathrm{HbA} 1 \mathrm{c} \leq 7.5 \%(\leq 58.0 \mathrm{mmol} /$ mol) (Bhansali et al., 2017). The results also showed that after 1 year of followup, the primary endpoint showed a reduction in insulin requirement by $\geq 50 \%$ from baseline, while maintaining $\mathrm{HbA} 1 \mathrm{c}<7.0 \%$ ( $<53.0 \mathrm{mmol} / \mathrm{mol})$. Specifically, 6 of $10(60 \%)$ treated patients achieved the primary endpoint and a significant reduction in insulin requirement at month 12 (Bhansali et al., 2017). In this study, Bhansali et al. (2017) also used bone marrow derived mesenchymal stem cells (BM-MSCs) to treat these T2DM patients. The authors in that publication showed that treatment efficacy of transplanted BM-MSCs is equivalent to transplanted BM-MNCs (Bhansali et al., 2017).

In another study, Liu et al. (2016) reported using MSCs derived from amniotic membrane to treat T2DM patients, with 3 years of follow-up (Liu et al., 2016). This study was carried out in 4 patients. These patients were transplanted with allogeneic neonatal amniotic membrane derived MSCs at $2 \times 10^{7}$ cells. The results showed that there was an improvement of glycemic control. Indeed, $100 \%$ of the patients did not require insulin but did need metformin (250-500 mg/day) to control blood glucose levels. However, by this therapy, there was no effect on Cpeptide. Therefore, the authors suggested that there was an increase of insulin sensitivity (Liu et al., 2016).

\section{How can stem cells treat T2DM?}

The specific mechanism of MSCs in T2DM treatment remains unclear. However, positive benefits from clinical treatment with MSC have suggested and led to investigations of mechanisms in T2DM patients. Some clinical trials have examined autologous versus allogeneic MSCs, and MSCs versus MNCs. Transplantation with each of them led to improvements in T2DM patients. Indeed, in allogenic transplantation of stem cells, grafted cells could not survive in the host for a long time. Therefore, some effects of stem cell transplantation cannot be from the homing or from differentiation of stem cells into insulin producing cells. Moreover, in the T2DM patients, the human body does not lack insulin. The study of Liu et al. (2016) showed that there was no change in Cpeptide concentrations, although there were improvements in blood glucose levels of T2DM patients. Thus, it is likely that stem cell transplantation cannot improve insulin production in T2DM patients.

However, stem cell transplantation may improve the insulin sensitivity of cells in certain tissues. To date, the reason for insulin resistance in T2DM patients has not been elucidated. Some recent studies have suggested that immune reactions, similar to those observed in autoimmune diseases, can cause insulin resistance to be observed in T2DM patients. Indeed, Antuna-Puente et al. (2008) and Sell et al. (2012) showed that chronic inflammation of adipose tissues 
significantly contributed to insulin resistance (Antuna-Puente et al., 2008; Sell et al., 2012). In some studies, it was also shown that insulin resistance in T2DM originated from inflammation. The inflammation could be related to abnormalities of lymphocytes, eosinophils, mast cells and dendritic cells (DeFuria et al., 2013; Liu et al., 2009; Musilli et al., 2011; Talukdar et al., 2012; Wu et al., 2011). If T2DM is an immune-related disease, MSC transplantation seems to be a suitable platform for T2DM therapy. Indeed, MSCs exert their immune modulation thorough suppressing T cells, B cells, natural killer (NK) cells and dendritic cells (DCs) (Le et al., 2016; Pham et al., 2016; Sangiorgi and Panepucci, 2016).

\section{Conclusion}

Although the study of MSC transplantation for T2DM is still young, there is great potential for its use, particularly for treating T2DM. Current breakthroughs in the understanding of mechanisms and biological characteristics of MSCs have suggested that MSC transplantation can be effective for T2DM. MSCs can persist in vivo without homing or and can differentiate into beta cells to produce insulin in the patients; however, grafted/transplanted cells can improve insulin resistance. Although the mechanism by which MSCs can improve insulin resistance remains unclear, its role in immune modulation to reduce local inflammation and insulin resistance are evident. Based on the benefits of MSCs, transplantation of MSCs may be a highly promising therapy for T2DM treatment.

\section{Abbreviations}

BM-MNCs: Bone marrow mononuclear cells

DCs: Dendritic cells

MSC: Mesenchymal stem cell

NK: Natural Killer cell

T1DM: Type 1 diabetes mellitus

T2DM: Type 2 diabetes mellitus

\section{References}


Antuna-Puente, B., Feve, B., Fellahi, S., and Bastard, J.P. (2008). Adipokines: the missing link between insulin resistance and obesity. Diabetes \& metabolism 34, 2-11.

Bhansali, S., Dutta, P., Kumar, V., Yadav, M.K., Jain, A., Mudaliar, S., Bhansali, S., Sharma, R.R., Jha, V., Marwaha, N., et al. (2017). Efficacy of Autologous Bone Marrow-Derived Mesenchymal Stem Cell and Mononuclear Cell Transplantation in Type 2 Diabetes Mellitus: A Randomized, Placebo-Controlled Comparative Study. Stem cells and development.

DeFuria, J., Belkina, A.C., Jagannathan-Bogdan, M., Snyder-Cappione, J., Carr, J.D., Nersesova, Y.R., Markham, D., Strissel, K.J., Watkins, A.A., Zhu, M., et al. (2013). B cells promote inflammation in obesity and type 2 diabetes through regulation of T-cell function and an inflammatory cytokine profile. Proceedings of the National Academy of Sciences of the United States of America 110, 5133-5138.

Le, P.T.-B., Duong, T.M., Vu, N.B., and Pham, P.V. (2016). Umbilical cord derived stem cell (ModulatistTM) transplantation for severe chronic obstructive pulmonary disease: a report of two cases. Biomedical Research and Therapy, 902-909\%V 903.

Liu, J., Divoux, A., Sun, J., Zhang, J., Clement, K., Glickman, J.N., Sukhova, G.K., Wolters, P.J., Du, J., Gorgun, C.Z., et al. (2009). Genetic deficiency and pharmacological stabilization of mast cells reduce diet-induced obesity and diabetes in mice. Nature medicine 15, 940-945.

Liu, Y., Guo, L.B., and Xu, J.K. (2016). Amniotic stem cell transplantation therapy for type 2 diabetes: 3 years' follow-up report. European review for medical and pharmacological sciences 20, 3877-3885.

Musilli, C., Paccosi, S., Pala, L., Gerlini, G., Ledda, F., Mugelli, A., Rotella, C.M., and Parenti, A. (2011). Characterization of circulating and monocyte-derived dendritic cells in obese and diabetic patients. Molecular immunology 49, 234-238.

Pham, P.V., Vu, N.B., and Phan, N.K. (2016). Umbilical cord-derived stem cells (MODULATISTTM) show strong immunomodulation capacity compared to adipose tissue-derived or bone marrow-derived mesenchymal stem cells. Biomedical Research and Therapy, 687-696\% 683.

Sangiorgi, B., and Panepucci, R.A. (2016). Modulation of Immunoregulatory Properties of Mesenchymal Stromal Cells by Toll-Like Receptors: Potential Applications on GVHD. Stem cells international 2016, 9434250.

Sell, H., Habich, C., and Eckel, J. (2012). Adaptive immunity in obesity and insulin resistance. Nature reviews Endocrinology 8, 709-716.

Talukdar, S., Oh, D.Y., Bandyopadhyay, G., Li, D., Xu, J., McNelis, J., Lu, M., Li, P., Yan, Q., Zhu, Y., et al. (2012). Neutrophils mediate insulin resistance in mice fed a high-fat diet through secreted elastase. Nature medicine 18, 1407-1412.

Wehbe, T., Chahine, N.A., Sissi, S., Abou-Joaude, I., and Chalhoub, L. (2016). Bone marrow derived stem cell therapy for type 2 diabetes mellitus. Stem cell investigation 3, 87.

Wu, D., Molofsky, A.B., Liang, H.E., Ricardo-Gonzalez, R.R., Jouihan, H.A., Bando, J.K., Chawla, A., and Locksley, R.M. (2011). Eosinophils sustain adipose alternatively activated macrophages associated with glucose homeostasis. Science (New York, NY) 332, 243-247.

Xv, J., Ming, Q., Wang, X., Zhang, W., Li, Z., Wang, S., Li, Y., and Li, L. (2016). Mesenchymal stem cells moderate immune response of type 1 diabetes. Cell and tissue research. 